\title{
Coal Moisture Variations in Response to Rainfall Events in Mine and Coal-Fired Power Plant Stockpiles-Part 2: Evaporation
}

\author{
Quentin Peter Campbell (D), Marco le Roux and Fardis Nakhaei *(D) \\ School of Chemical and Minerals Engineering, North-West University, Potchefstroom 2531, South Africa; \\ quentin.campbell@nwu.ac.za (Q.P.C.); Marco.LeRoux@nwu.ac.za (M.1.R.) \\ * Correspondence: 36598704@nwu.ac.za; Tel.: +27-661-031-248
}

check for updates

Citation: Campbell, Q.P.; le Roux, M.; Nakhaei, F. Coal Moisture Variations in Response to Rainfall Events in Mine and Coal-Fired Power Plant Stockpiles-Part 2: Evaporation. Minerals 2021, 11, 1366. https:// doi.org $/ 10.3390 / \min 11121366$

Academic Editor: Carlito Tabelin

Received: 20 October 2021

Accepted: 19 November 2021

Published: 3 December 2021

Publisher's Note: MDPI stays neutral with regard to jurisdictional claims in published maps and institutional affiliations.

Copyright: (C) 2021 by the authors. Licensee MDPI, Basel, Switzerland. This article is an open access article distributed under the terms and conditions of the Creative Commons Attribution (CC BY) license (https:// creativecommons.org/licenses/by/ $4.0 /)$.

\begin{abstract}
Additional moisture added in coal stockpiles due to rain and other climatic processes causes a significant problem worldwide, which leads to not only decrease in the heating value of the coal but also creates an extra efficiency penalty. Therefore, it is important to make some predictions for control of coal moisture within stockpiles after the rainfall. When the rain falls on the stockpile, it either runs off the surface or infiltrates the stockpile. The infiltrated water may evaporate from the surface, drain or stay within the stockpile. The aims of this study (parts 1 and 2) are to describe and compare the changes in coal moisture content following rainfall events. The mechanisms of runoff, infiltration and drainage after rainfall were described in the first paper of this series. In part 2 the influence of coal particle size and ambient conditions on the rate and depth of moisture evaporation within the stockpile is investigated. The laboratory experiments showed cyclic events of adsorbing moisture overnight and desorbing this moisture during the day as part of the coal surface evaporation process. The rate of evaporation from the surface of the fine coal stockpile was faster than the coarse stockpile; however, the coarse stockpile experienced a more efficient evaporation process because of its porous structure. Fine coal beds experienced evaporation only near the surface, while the maximum influencing layer of evaporation is a depth of $0.4 \mathrm{~cm}$ below the surface in coarse coal beds.
\end{abstract}

Keywords: coal stockpile; rainfall; simulation; moisture; evaporation

\section{Introduction}

As many thermal power plants are placed far away from coal mines and concentrators, for balanced operations, storage of coal in an open stockpile for a month of electricity generation is essential to dealing with any problems in coal mines or transport networks. Similar actions are also considered for coast-based utilities which depend on imported or exported coal. Additionally, depending on the fluctuations in the international prices of coal, big plants purchase large amounts of coal when the price is low and then store it for a long time (120 days). Coal stockpiles are generally left uncovered due to the need for frequent loading and unloading [1]. Coal stockpiling for a long period causes the coal to be exposed to atmospheric conditions such as rainfall.

In South Africa, about $92 \%$ of total electricity generation comes from coal-based thermal power plants; the country is the world's seventh largest coal consumer. The total coal consumption in South Africa was 202 Million Tons (MT) during the year 2016-2017, which was about 17.5 MT per month [2]. Coal is generally stored in open stockpiles in the storage yard with capacities of about 50,000-200,000 tons for an average of 10 to 30 days' requirement of the power plant. Unfortunately, coal stockpiles are almost always susceptible to rain, which influences the final moisture content of the coal. Excessive moisture of coal is one of the serious problems within coal yards of power plants. It results in an economic loss and a reduced calorific value of the coal.

When rain falls on the surface of an uncovered stockpile, the water infiltrates into the pile, evaporates back to the atmosphere, or flows off the pile surface as runoff $[3,4]$. The 
amount of runoff water from the pile depends on the hydraulic properties of the stockpile surface. When water infiltrates the stockpile, it can either by stored by the capillary properties of waste rock material or it can flow directly through the pile as outflow. The amount of water that infiltrates into the stockpile depends on the infiltration capacity of the surface, coal particle size distribution (PSD), amount and intensity of rainfall, and internal moisture content of the stored coal $[5,6]$. The rate of evaporation is mainly influenced by the weather conditions, such as sunlight, temperature, wind speed and relative humidity as well as physical and chemical characterization of coal particles $[7,8]$.

To control the moisture content in coal stockpiles after rainfall, the mechanisms by which water moves within a stockpile must be properly understood. It is very important for coal washing and power plants to understand the effect of coal particle size, rate of compaction and weather conditions on runoff, infiltration, drainage and evaporation rates within stockpiles. The amount of time required for the requisite amount of drainage and evaporation as well as removing moisture is unique to every stockpile and set of environmental conditions. Moreover, the operators need to know which part of the stockpile should be used with the least moisture after a rainfall. These issues are not obvious to coal-fired plant operators, who face serious problems due to the coal moisture. Therefore, extensive research is needed in this area. There are some studies that investigate the changes in soil moisture content following rainfall. These surveys simulated the phenomena of evaporation and infiltration in terms of soil water resources, which play critical roles in the hydrological cycle system, agriculture or plantations and improvement of ecosystems [9-11]. Experimental data relating to the characteristics and processes of water movement after rainfall in coal stockpile are limited [12,13].

There is a need for more detailed investigations of the general behavior of moisture movement and multi-factor effects on coal moisture levels after rainfall which are the main objective of this series of papers. The mechanisms of runoff, infiltration and drainage within a coal stockpile after rainfall have been experimentally investigated in the first paper of this series. The results showed that rainfall intensity, stockpile slope, fines content and the degree of compaction can strongly affect the surface runoff and infiltration rates. Particle size distribution, the height of the stockpile and coal type have also been found to have a significant influence on the dewatering efficiency of drainage. The purpose of Part 2 of this study is to evaluate the influences of coal particle size and ambient conditions on the rate and depth (zone) of moisture evaporation within the stockpile that was not investigated in part A of this paper. This study will provide a comprehensive guide for the prediction and control of excessive moisture in a coal stockpile.

\section{Materials and Methods}

\subsection{Materials}

During this investigation, a coal B (fairly low rank) sample obtained from Witbank region of South Africa was used. The particle size, proximate analysis, calorific values and XRD analysis of sample were detailed in the first paper of this series.

The proximate analysis indicated that the representative sample contained $15.9 \%$ ash and $56.4 \%$ total fixed carbon. The inherent moisture content of the coal was $2.6 \%$ wt. XRD analysis revealed that the main mineral composition of coal gangue is kaolinite (about $13 \%$ ). Three different particle sizes, $13.2+6.7 \mathrm{~mm},-13.2+0 \mathrm{~mm}$ and $-6.7+0 \mathrm{~mm}$, were used in the present study.

\subsection{Experimental Design}

The aim of this study is to investigate the effect of coal stockpile bed particle size and weather conditions on the rate and depth of moisture evaporation. The experiments were divided into two parts. For the first part of the experiment, wet coal samples were loaded into two containers $(34 \mathrm{~cm} \times 25 \mathrm{~cm} \times 20 \mathrm{~cm})$ to simulate the rate at which moisture evaporates from a coal stockpile surface. The second part was conducted to estimate the depth to which evaporation extends. In both parts, water-saturated samples of three 
different size ranges: $-13.2+6.7 \mathrm{~mm},-13.2+0 \mathrm{~mm}$ and $-6.7+0 \mathrm{~mm}$, were used as a starting condition.

Evaporation rate from a coal surface was determined by measuring the mass loss from containers (placed on load cells) exposed to the atmosphere (Figure 1a), while the weather conditions, such as relative humidity and temperature, were measured at the same time. Coal samples with known mass and PSD were placed into the containers to a depth of about $25 \mathrm{~cm}$ and saturated with water. The extra water was drained off, and a sample was taken as an initial moisture content. The experiments were run for 10 days.

(a)

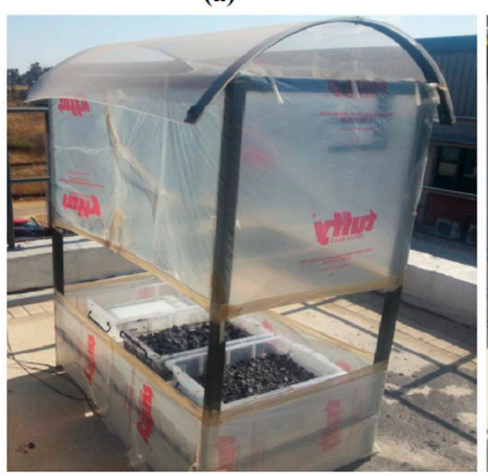

(b)

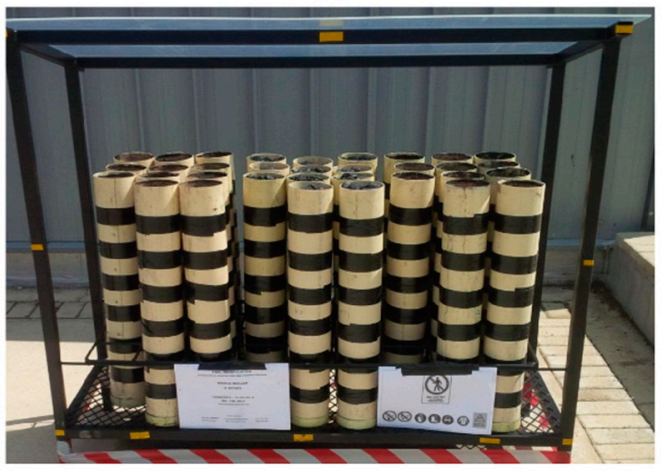

Figure 1. Evaporation experimental setup. (a) The shallow containers (b) multiple evaporation pipes. Both structures were covered with Perspex roofs.

The depth to which evaporation occurs was investigated by using the experimental setup shown in Figure 1b. Samples were loaded into 36 sectioned $70 \mathrm{~cm}$ long PVC pipes (12 pipes for each particle size range) and located outside for 10 days while exposed to ambient conditions. Each pipe consisted of 7 segments with a height of $10 \mathrm{~cm}$ that were taped together to form a cohesive pipe. Water was added to each pipe to saturate the coal and the free water was allowed to drain out at the bottom covered with filter cloth to prevent fine and ultrafine particles from exiting with the free water. Once drainage had ceased, the bottoms of the pipes were sealed. Therefore, the change in the water storage was due only to the water loss of evaporation from the coal, namely the water loss in the coal should be equal to the amount of evaporation. The first pipe was sampled before any evaporation could occur to establish the initial moisture profile. One pipe per size was selected for determination of coal moisture content every day (at 13:00).

\section{Results}

\subsection{Evaporation from the Coal Stockpile Surface}

The evaporation of moisture from coal particles is a diurnal cyclic event (Figure 2) and is related to the ambient conditions due to equilibrium with the surrounding atmosphere. This diurnal pattern for surface moisture content derived from evaporation during daytime and subsequent coal rewetting during nighttime. The evaporation rate is higher during the day when the temperatures are higher, but at nighttime, reabsorption of moisture into the porous particles occurs due to lower temperatures and the higher relative humidity of the surroundings. It can be seen that the cycles are small initially, as the bed was still somewhat saturated. A high rate of evaporation during the day will lead to drier coal particles, meaning that the reabsorption capacity of the coal bed will be higher. This pattern during evaporation process was consistent with the results from previous studies $[9,14]$.

\subsection{Influence of Weather Conditions}

Figure 3 shows the influence of environmental temperature, relative humidity and the resultant partial pressure of water on the evaporation rate from a flat coal bed. An increase in temperature led to an increase in the rate of evaporation, as was expected (Figure 3a). The moisture content near the coal surface showed a diurnal pattern, which decreased from 
mid-morning through the afternoon and then increased from afternoon to mid-morning on the next day. Evaporation happened between 09:00 and 17:00, with a maximum around 12:00. After sunset, the temperature dropped and there was a corresponding increase in the relative humidity. The troughs seen in the rate of evaporation in Figure 3 occurred during these conditions, which led to the coal particles reabsorbing moisture from the atmosphere. This resulted in a negative evaporation rate. An inverse relationship between the rate of evaporation and relative humidity is evident in Figure $3 \mathrm{~b}$. The ratios of evaporation showed a clear tendency to increase with a reduction in the relative humidity.

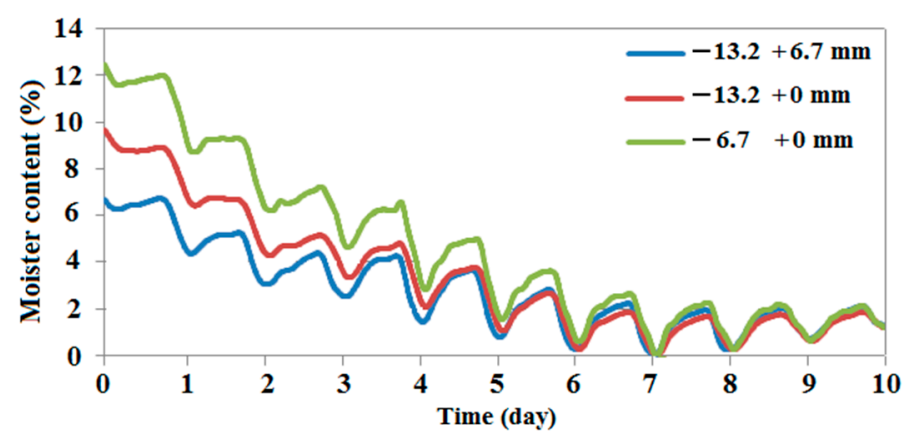

Figure 2. Decrease in moisture content for coal B (14-24 July) at different particle size distributions $(-13.2+6.7 \mathrm{~mm},-13.2+0 \mathrm{~mm}$ and $-6.7+0 \mathrm{~mm})$.

(a)

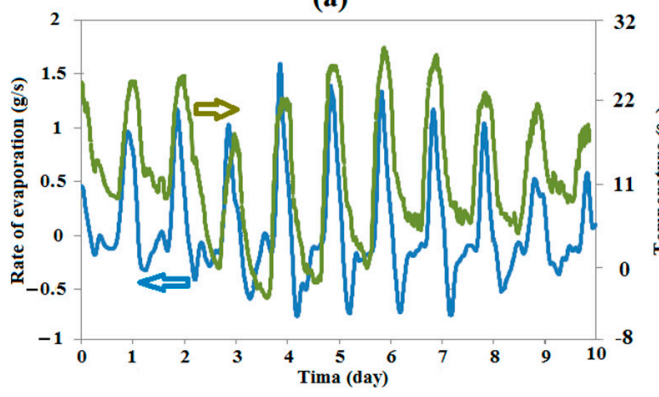

(b)

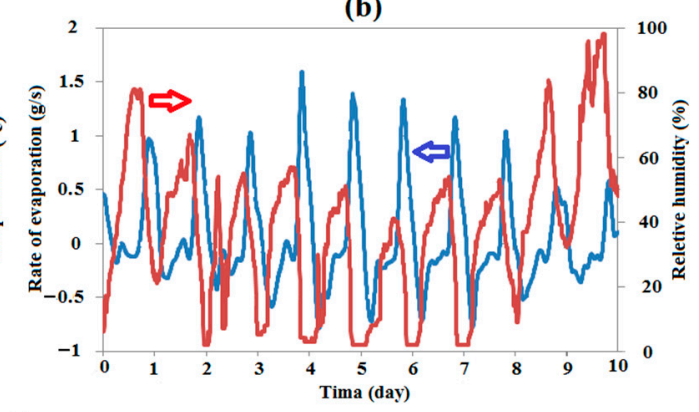

(c)

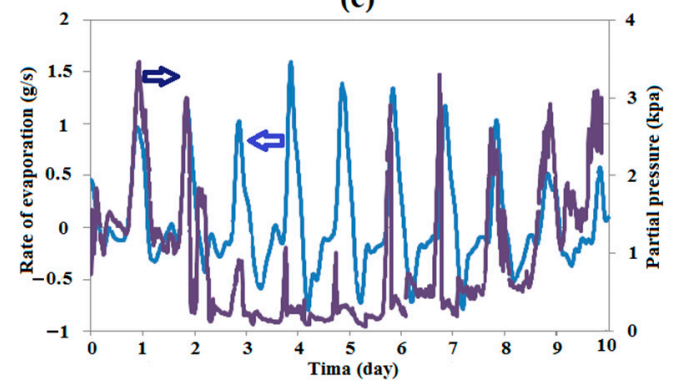

Figure 3. Comparison between the rate of evaporation and (a) temperature, (b) relative humidity and (c) partial pressure (Coal B; $-13.2+6.7 \mathrm{~mm} ; 14-24$ July).

The vapor pressure at the surface of the coal bed is totally higher than the atmospheric vapor pressure or relative humidity (Figure 3c), which resulted in the water molecules moving from the high to the lower pressure. The temperatures at which evaporation started on a daily basis ranged from $16^{\circ} \mathrm{C}$ to $24^{\circ} \mathrm{C}$, while relative humidity ranged from $4 \%$ to $53 \%$. The moisture content available for evaporation played a large role in determining the rate of evaporation.

Figure 4a shows that, during the day, the rate of evaporation increased as the temperature increased up to a maximum and then decreased until no further evaporation occurred. This decrease is attributed to the decline in moisture content available for evaporation as the day progressed. It is shown in Figure $4 \mathrm{~b}$ that the maximum rate of evaporation 
occurred earlier at the start of a run than at the end. The maximum rate of evaporation also decreased as the coal bed becomes drier over time.

(a)

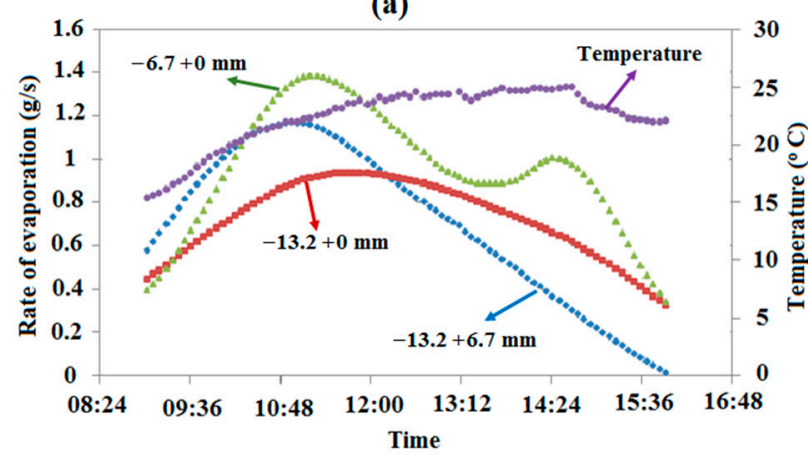

(b)

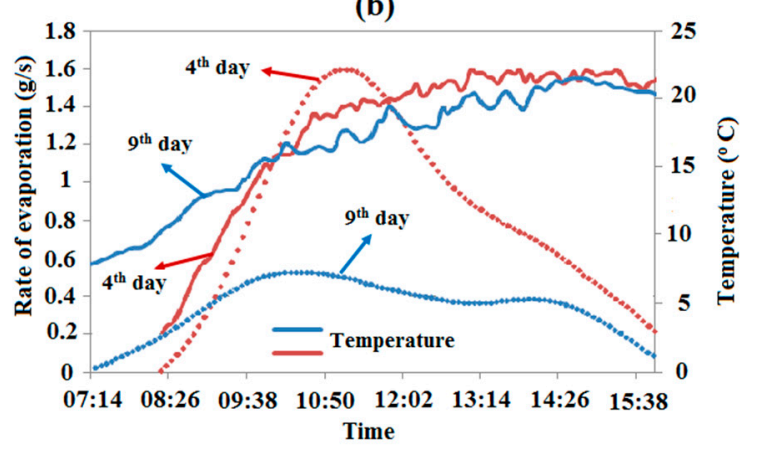

Figure 4. (a) A daily cycle of the rate of evaporation from a coal B surface in 2nd day and (b) A comparison between the daily rate of evaporation for a coal $\mathrm{B}-13.2 \mathrm{~mm}+0 \mathrm{~mm}$ surface.

\subsection{Influence of PSD}

Figure 5 illustrates the effect of PSD on the daily evaporation rate. The coal bed consisting of fine particles $(-6.7 \mathrm{~mm}+0 \mathrm{~mm})$ initially evaporated at a higher rate than the other coal samples. This occurrence is attributed to the fact that the fine coal sample has a larger surface area which leads to a higher rate of evaporation. However, after three days the rate of evaporation of coarse particles $(-13.2 \mathrm{~mm}+6.7 \mathrm{~mm})$ was higher compared to that of the fine coal bed. This is ascribed to the porous structure of the coarse particles. Additionally, as the moisture front moved downwards, and went deeper into the coal bed, the expulsion of the water vapor from the bed was hindered by the small spacing between the particles. This resulted in a reduction in the rate of evaporation.

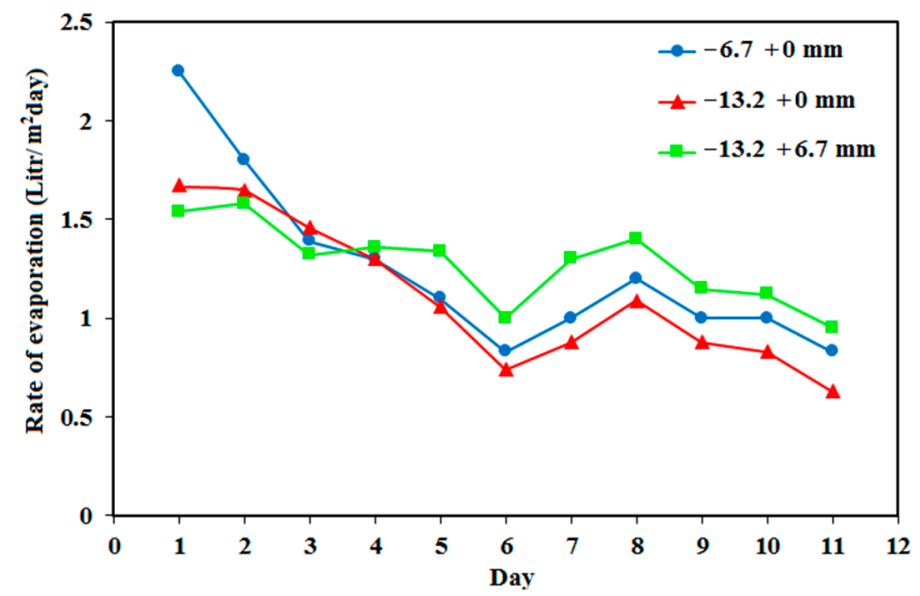

Figure 5. Influence of PSD on the daily rate of evaporation for coal B at different particle size distributions $(-13.2+6.7 \mathrm{~mm},-13.2+0 \mathrm{~mm}$ and $-6.7+0 \mathrm{~mm})$.

The coarse coal bed was more porous, which means that the removal of water vapor is less obstructed, and this aided the evaporation process. It can thus be inferred that the evaporation in on surface of a fine coal stockpile is faster than that of a coarse stockpile; however, the coarse stockpile will experience evaporation more efficiently because of its porous structure. The mixed coal bed $(-13.2+0 \mathrm{~mm})$ generally experienced the slowest rate of evaporation. This is attributed to the combination of the decreased surface area due to the larger particles and the minimal void spacing between the smaller particles. 


\subsection{Influence of Depth}

To investigate the depth to which evaporation will extend, several segmented pipes were constructed and used to track the migration of moisture. It is shown in Figure 6 that the total moisture content decreased over time for all coal samples, as the moisture evaporated from the surface of the coal. Water contents near the bed surface decreased rapidly for the first few days, caused by gravity drainage and evaporation imposed by the hot and dry atmospheric conditions. Some drainage occurred within the samples, shown by the steady increase in moisture towards the bottom of the container.

(a)
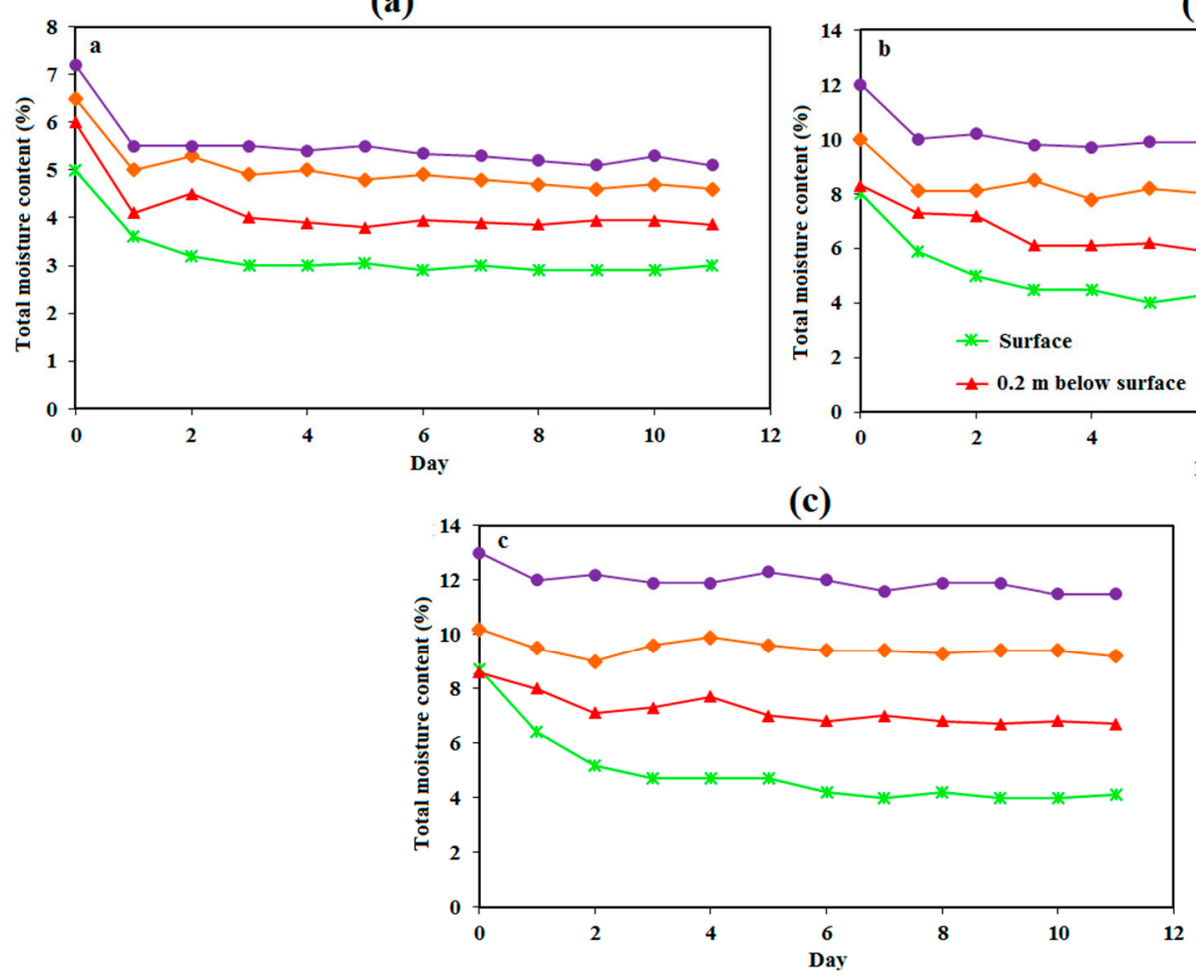

(b)

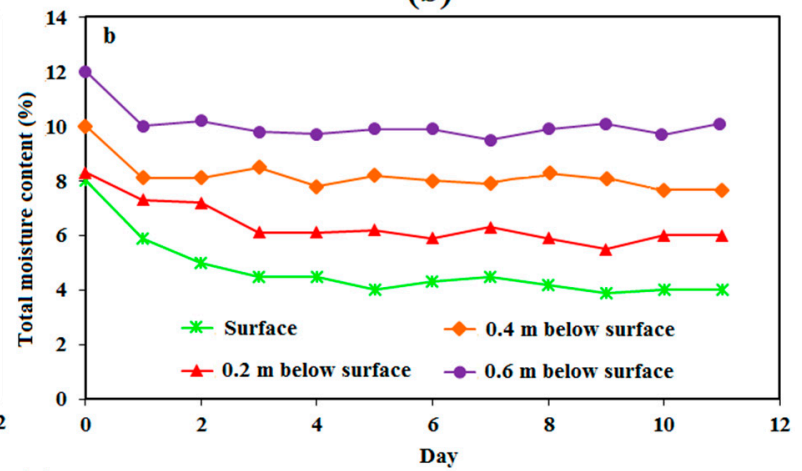

Day

\section{.}


No significant evaporation deeper into the coal bed was observed. This is attributed to the low porosity of the coal bed.

The variabilities in the water content of deeper coal layers were lower than those of shallow coal layers, which was due to the shallow coal layers being more susceptible to the changes in the external environment. It can be concluded that the coal particle size range had less influence on the amount of moisture evaporation at a depth $>0.4 \mathrm{~m}$, but it had a significant effect on the extent of evaporation from the coal surface.

All coal samples reached a steady state at day 4 because there was no more free moisture for evaporation and the total moisture content remained nearly constant. In addition, the maximum influencing depth of evaporation was $0.4 \mathrm{~m}$, and no significant differences were found at the $0.4-0.7 \mathrm{~m}$ depth between the coal water content and the daily evaporation amount. It is suggested that a $0.4 \mathrm{~m}$ layer of coal can be reclaimed from stockpiles and the residual coal should be exposed to weathering to dry for another four days. In general, many small stockpiles are preferred to one big one.

\section{Conclusions}

Stockpiling of coal for a long time causes the coal to be exposed to atmospheric conditions and rainfall. Since excessive moisture of coals results in economic loss and a reduced calorific value of coal, it is essential to know a moisture movement pattern and the parameters effective in the control of coal moisture stored in stockpiles before burning in the boiler. The purposes of this study are (a) simulation of evaporation processes within coal stockpiles and (b) investigation of the effect of coal particle size and ambient conditions on the rate and depth of moisture evaporation. The following outcomes from this research are summarized:

- An increase in temperature and a reduction in the relative humidity led to an increase in the rate of evaporation. The coal stockpile surface moisture indicated cyclic events of adsorbing moisture overnight (as the temperature fell and the relative humidity increased) and desorbing this moisture during the day as parts of the evaporation process. This occurrence is attributed to the coal particles trying to be in moisture equilibrium with the surrounding air.

- The PSD of coal had smaller influence on the amount of moisture evaporation at a depth $>0.4 \mathrm{~m}$, but it had a remarkable effect on the extent of evaporation from the coal surface.

- The evaporation on the surface of a fine coal stockpile is faster than that of a coarse stockpile, but the coarse stockpile will experience evaporation more efficiently due to its porous structure.

- The fine coal bed only experienced evaporation on the surface, while the coarse coal showed signs of evaporation up to $0.4 \mathrm{~m}$ below the surface. The maximum effective depth of evaporation is $0.4 \mathrm{~m}$ below the coal stockpile surface.

- This paper will be useful for coal producers and consumers to estimate the optimum duration of time coal should remain in stockpiles after rainfall. The results of this paper can be used for the effective management of coal stockpile to prevent excessive moisture in stockpiles for best possible utilization of coal in power plants.

Author Contributions: Conceptualization, Q.P.C. and M.l.R.; supervision, Q.P.C.; methodology, Q.P.C.; test and analysis, Q.P.C., M.l.R. and F.N.; writing—original draft preparation, F.N.; writingreview and editing, F.N. and Q.P.C. All authors have read and agreed to the published version of the manuscript.

Funding: This research was funded by [Coaltech Research Association NPC] and [the South Africa National Research Foundation THRIP programme] grant number [TP14081289982] and The APC was funded by North West University.

Data Availability Statement: Data sharing is not applicable. 
Acknowledgments: The authors would like to acknowledge the support of the Coaltech and Eskom for this research.

Conflicts of Interest: The authors declare no conflict of interest.

\section{References}

1. Schulz, D.; Schwindt, N.; Schmidt, E.; Kruggel-Emden, H. Modelling of dust emissions induced by flow over stockpiles and through packed beds. Particuology 2020, 59, 55-63. [CrossRef]

2. Coal Consumption by Country. 2016. Available online: https://www.worldometers.info/coal/coal-consumption-by-country/ \#south-africa (accessed on 12 October 2020).

3. Chen, J.; Williams, K.; Guo, J.; Chen, W. Theoretical and experimental investigation into the moisture migration char-acteristics of coal during oscillatory motion. Powder Technol. 2019, 342, 764-772. [CrossRef]

4. Campbell, Q.P.; le Roux, M. Moisture retention and migration in a coal product stockpile. In Proceedings of the IMPC 2014, Santiago, Chile, 20 October 2014.

5. Curran, K.J.; Droppo, I.G.; Irvine, K.N. Hydrology of stockpiled industrial coal exposed to rainfall. Hydrol. Process. 2002, 16, 2781-2790. [CrossRef]

6. Wels, C.; Louden, S.; Fortin, S. Factors Influencing Net Infiltration into Mine Rock piles at Questa Mine New Mexico. 2015. Available online: https:/ / www.rgc.ca/files/publications/welfin.pdf (accessed on 8 August 2015).

7. Deodhar, M.J. Elementary Engineering Hydrology; Pearson Education, Dorling Kindersley: New Delhi, India, 2008.

8. Karthikeyan, M. Minimization of Moisture Readsorption in Dried Coal Samples. Dry. Technol. 2008, 26, 948-955. [CrossRef]

9. Han, J.; Lin, J.; Dai, Y. Numerical Modeling of Soil Evaporation Process and Its Stages Dividing during a Drying Cycle. Geofluids 2017, 2017, 5892867. [CrossRef]

10. Liao, Y.; Cao, H.-X.; Liu, X.; Li, H.-T.; Hu, Q.-Y.; Xue, W.-K. By increasing infiltration and reducing evaporation, mulching can improve the soil water environment and apple yield of orchards in semiarid areas. Agric. Water Manag. 2021, 253, 106936. [CrossRef]

11. Heitman, L.; Horton, R.; Sauer, T.J.; DeSutter, T.M. Sensible heat observations reveal soil-water evaporation dynamics. J. Hydrometeorol. 2008, 9, 165-171. [CrossRef]

12. Campbell, Q.; Le Roux, M.; Espag, C. Coal product moisture control using stockpiles. In Proceedings of the XVIII International Coal Preparation Congress, Saint-Petersburg, Russia, 28 June-1 July 2016; Litvinenko, V., Ed.; Springer: Cham, Switzerland, 2016. [CrossRef]

13. Eckersley, J.D. Moisture Changes and Stability Problems in Coal Stockpiles, Final Report, Australian Coal Association Research Program Project C4057; University of North Queensland: Brisbane, Australia, 1999.

14. Verhoef, A.; Fernandez-Galvez, J.; Diaz-Espejo, A.; Main, B.E.; El-Bishti, M. The diurnal course of soil moisture as measured by various dielectric sensors: Effects of soil temperature and the implications for evaporation estimates. J. Hydrol. 2006, 321, 147-162. [CrossRef]

15. Lian, H.; Yi, H.; Yang, Y.; Wu, B.; Wang, R. Impact of Coal Mining on the Moisture Movement in a Vadose Zone in Open-Pit Mine Areas. Sustainability 2021, 13, 4125. [CrossRef] 